\title{
Mitogen-activated Protein Kinase (ERK1/2) Activation by Shear Stress and Adhesion in Endothelial Cells

\author{
Essential Role for a Herbimycin-sensitive Kinase
}

Masafumi Takahashi and Bradford C. Berk

Department of Medicine, Division of Cardiology, University of Washington, Seattle, Washington $98195-7710$

\begin{abstract}
Fluid shear stress modulates vascular function and structure by stimulating mechanosensitive endothelial cell signal events. Cell adhesion, mediated by integrin-matrix interactions, also regulates intracellular signaling by mechanosensitive events. To gain insight into the role of integrin-matrix interactions, we compared tyrosine phosphorylation and extracellular signal-regulated kinase (ERK1/2) activation in adhesion- and shear stress-stimulated human umbilical vein endothelial cells (HUVEC). Adhesion of HUVEC to fibronectin, but not to poly-L-lysine, rapidly activated ERK1/2. Fluid shear stress $\left(12 \mathrm{dyn} / \mathrm{cm}^{2}\right)$ enhanced ERK1/2 activation stimulated by adhesion, suggesting the presence of a separate pathway. Two differences in signal transduction were identified: focal adhesion kinase phosphorylation was increased rapidly by adhesion but not by shear stress; and ERK1/2 activation in response to adhesion was inhibited to a significantly greater extent when actin filaments were disrupted by cytochalasin $D$. Two similarities in activation of ERK1/2 were observed: protein kinase $\mathrm{C}$ (PKC) activity was necessary as shown by complete inhibition when PKC was downregulated; and an herbimycin-sensitive (genistein- and tyrphostin-insensitive) tyrosine kinase was required. c-Src was identified as a candidate tyrosine kinase as it was activated by both shear stress and adhesion. These findings suggest that adhesion and shear stress activate ERK1/2 via a shared pathway that involves an herbimycin-sensitive tyrosine kinase and PKC. In addition, shear stress activates ERK1/2 through another pathway that is partially independent of cytoskeletal integrity. (J. Clin. Invest. 1996. 98:2623-2631.) Key words: mechanical stress • signal transduction • tyrosine kinase $\cdot$ focal adhesion contact $\bullet$ cytoskeleton
\end{abstract}

\section{Introduction}

Mechanical forces alter the structural and functional properties of cells of the cardiovascular system at the cellular and molecular levels with profound effects on physiology. Fluid shear

Address correspondence to Bradford C. Berk, M.D., Ph.D., University of Washington, Division of Cardiology, Box 357710, Seattle, WA 98195-7710. Phone: 206-685-6960; FAX: 206-616-1580; E-mail: bcberk @u.washington.edu

Received for publication 8 April 1996 and accepted in revised form 30 September 1996.

J. Clin. Invest.

(C) The American Society for Clinical Investigation, Inc.

0021-9738/96/12/2623/09 \$2.00

Volume 98, Number 11, December 1996, 2623-2631 stress is one of the most important mechanical forces experienced by endothelial cells because of their location at the interface between the vessel surface and the blood. Recent evidence indicates that shear stress modulates vascular structure and function by activating specific signal events leading to activation of transcription factors and changes in gene expression (1). For example, increases in activity of intracellular signaling molecules (e.g., intracellular calcium $(2,3)$, mitogen-activated protein (MAP) ${ }^{1}$ kinase (extracellular signal-regulated kinase 1/2; [ERK1/2; 4], and c-Jun- $\mathrm{NH}_{2}$-terminal kinase [JNK; 5], activating protein-1 [AP-1] transcription factor [6]), and changes in shear stress responsive genes (e.g., PDGF; 7, monocyte chemoattractant protein-1 [MCP-1; 8], and endothelin-1 [9]) have been demonstrated. We recently showed that ERK1/2 activation by shear stress in bovine aortic endothelial cells is protein kinase C (PKC)-dependent and calcium-independent (4). ERK1/2 was first identified as a microtubule-associated protein kinase (10) and has been shown to phosphorylate proteins and to regulate gene expression. For instance, ERK1/2 phosphorylates both p90rsk, an S6 protein kinase that stimulates protein synthesis $(11,12)$, and $\mathrm{p} 62^{\mathrm{TCF}}$, a transcription factor that increases $c$-fos transcription (13). Although the pathways leading from growth factor receptor activation to ERK1/2 stimulation have been well characterized (14), the pathways leading to activation of ERK1/2 by shear stress remain unclear.

We have recently suggested that integrin-mediated signal events may be important in shear stress-mediated signal transduction (15), based on findings that shear stress-stimulated focal adhesion kinase (FAK) tyrosine phosphorylation (peak at $2 \mathrm{~h}$ ), and activation of $\beta_{1}$ integrins in human umbilical vein endothelial cells (HUVEC) stimulate ERK1/2 activity. Integrins are ubiquitous $\alpha / \beta$ heterodimeric transmembrane glycoproteins, which act as adhesion receptors involved in the interaction between cell and extracellular matrix (ECM) (16). It has become clear that integrin activation stimulates many intracellular signal events, several of which resemble those stimulated by shear stress in endothelial cells. For example, both shear stress and integrins affect intracellular $\mathrm{pH}(17,18)$, intracellular calcium (19), tyrosine phosphorylation $(20,21)$, inositol lipid metabolism $(3,22)$, and ERK1/2 activity $(23,24)$. Several studies indicate that integrins play a crucial role in mechanosensitive signal events (25-27). A specific role for integrins in shear stress signal transduction is suggested by the finding that shear stress induces rapid remodeling of focal adhesion contacts $(28,29)$. Because focal adhesion contacts are formed at

1. Abbreviations used in this paper: ERK1/2, extracellular signal-regulated kinase; FAK, focal adhesion kinase; FN, fibronectin; HUVEC, human umbilical vein endothelial cells; MAP, mitogen-activated protein; PKC, protein kinase C; PLL, poly-L-lysine. 
the sites of linkage of the cytoplasmic tails of integrins with cytoskeletal proteins and are thought to play a key role in integrin signal transduction, we hypothesized that integrins may act as mechanotransducers of shear stress.

In this study, we compared tyrosine phosphorylation and ERK1/2 activation in adhesion- and shear stress-stimulated HUVEC. Both integrin-mediated adhesion and shear stress stimulated ERK1/2 in a PKC-dependent and herbimycin-sensitive manner, indicating shared signal events. However, shear stress activated ERK1/2 by a pathway separate from adhesion as shown by three findings: $(a)$ shear stress was additive with adhesion for ERK1/2 activation; (b) ERK1/2 activation in response to adhesion was inhibited to a significantly greater extent by cytochalasin D; and (c) FAK was rapidly tyrosine phosphorylated by adhesion (peak at $15 \mathrm{~min}$ ) while FAK was slowly tyrosine phosphorylated by shear stress (peak at 120 $\min ; 15)$.

\section{Methods}

Cell culture and materials. HUVEC were obtained from umbilical cord veins as previously described (30). Cells at passages between 1 and 3 were grown in RPMI-1640 (GIBCO BRL, Gaithersburg, MD) supplemented with $20 \%$ FBS (Hyclone Laboratories, Inc., Logan, UT), heparin (Sigma Chemical Co., St. Louis, MO), and endothelial cell growth factor (kindly provided by Dr. R. Ross, University of Washington, Seattle, WA), and used at confluence. Herbimycin A, tyrphostin 23, and genistein were purchased from Calbiochem Novabiochem Intl. All experiments were performed at least three times using different preparations of HUVEC.

Cell adhesion assay. HUVEC were incubated at $37^{\circ} \mathrm{C}$ in $2 \mathrm{mM}$ ethylenediamine tetra-acetic acid (EDTA) in PBS $(137 \mathrm{mM} \mathrm{NaCl}$, $2.7 \mathrm{mM} \mathrm{KCl}, 4.3 \mathrm{mM} \mathrm{Na}_{2} \mathrm{HPO}_{4}, 1.4 \mathrm{mM} \mathrm{KH}_{2} \mathrm{PO}_{4}, \mathrm{pH}$ 7.3) for $5 \mathrm{~min}$ and detached from dishes by gentle pipetting. The cells were washed three times with RPMI 1640, collected by low speed centrifugation and resuspended in RPMI-1640 with 0.1\% BSA (Sigma Chemical Co.). $10^{6}$ cells were placed onto $60-\mathrm{mm}$ bacteriologic plastic dishes coated with fibronectin (FN; Sigma Chemical Co.) or poly-L-lysine (PLL; Sigma Chemical Co.) and incubated at $37^{\circ} \mathrm{C}$. The bacteriological plastic dishes and plates were coated with human FN $(10 \mu \mathrm{g} / \mathrm{ml})$ or PLL $(10 \mu \mathrm{g} / \mathrm{ml})$ for $16 \mathrm{~h}$ at $4^{\circ} \mathrm{C}$, and nonspecific binding sites were blocked with $1 \%$ heat denatured BSA in PBS for $1 \mathrm{~h}$ at room temperature. Before use the dishes and plates were rinsed three times with PBS.

Shear stress experiments. HUVEC were placed onto $2 \times 4 \mathrm{~cm}$ slides made of bacteriological plastic coated with human FN as described above. Preliminary experiments showed that cell density (range $5 \times 10^{5}$ to $2 \times 10^{6}$ cells/slide) had no significant effect on ERK1/2 activation by adhesion and shear stress. After the cells were incubated at $37^{\circ} \mathrm{C}$ for various times, the cells $\left(10^{6}\right)$ were rinsed free of culture media with Hepes-buffered saline solution (HBSS; $130 \mathrm{mM}$ $\mathrm{NaCl}, 5 \mathrm{mM} \mathrm{KCl}, 1.5 \mathrm{mM} \mathrm{CaCl}_{2}, 1.0 \mathrm{mM} \mathrm{MgCl}_{2}, 20 \mathrm{mM}$ Hepes, $\mathrm{pH}$ 7.4) with $10 \mathrm{mM}$ glucose and either maintained in static condition or exposed to fluid shear stress in a parallel plate chamber at $37^{\circ} \mathrm{C}$ exactly as described previously (4). To harvest cells, the plates were washed gently with ice-cold PBS and cell lysates prepared for in-gelkinase assay and Western blot analysis.

In-gel-kinase assay. Cells were lysed in $0.2 \mathrm{ml}$ of modified cell lysis buffer (10 mM Hepes, pH 7.4, 5 mM EDTA, 5 mM EGTA, $50 \mathrm{mM}$ sodium pyrophosphate, $50 \mathrm{mM} \mathrm{NaF}, 50 \mathrm{mM} \mathrm{NaCl}, 100 \mu \mathrm{M} \mathrm{Na} \mathrm{VO}_{4}$, $0.1 \%$ Triton X-100, and fresh $0.1 \mathrm{mM}$ PMSF and $10 \mu \mathrm{g} / \mathrm{ml}$ leupeptin). Cell lysates were prepared by freezing in liquid nitrogen, thawing on ice, scraping, and sonication. After centrifugation for $30 \mathrm{~min}$ at 14,000 rpm in a microfuge $\left(4^{\circ} \mathrm{C}\right)$ protein concentration was determined and the samples were stored at $-80^{\circ} \mathrm{C}$. In-gel-kinase assay using myelin basic protein as substrate was performed exactly as described previously (31). We have previously shown an excellent correlation be- tween ERK1/2 activity measured by in-gel-kinase assay and Western blot band shift $(4,31)$.

Immunoprecipitation and immunoblotting. After treatment, cells were washed with PBS, and $0.5 \mathrm{ml}$ of radioimmuno protein assay (RIPA) lysis buffer (10 mM Hepes, pH 7.4, 5 mM EDTA, $50 \mathrm{mM}$ sodium pyrophosphate, $50 \mathrm{mM} \mathrm{NaF}, 50 \mathrm{mM} \mathrm{NaCl}, 100 \mu \mathrm{M} \mathrm{Na} \mathrm{VO}_{4}$, $1 \%$ Triton X-100, $1 \%$ deoxycholic acid, $0.1 \%$ SDS, and fresh $0.5 \mathrm{mM}$ PMSF and $10 \mu \mathrm{g} / \mathrm{ml}$ leupeptin) was added. Cell lysates were prepared by scraping, sonication, and centrifugation for $5 \mathrm{~min}$ at $14,000 \mathrm{rpm}$ in a microfuge $\left(4^{\circ} \mathrm{C}\right)$. The lysates were immunoprecipitated and immune complexes were recovered by the addition of protein G-agarose (GIBCO BRL) or protein A-Sepharose CL-4B, incubation for $3 \mathrm{~h}$ at $4^{\circ} \mathrm{C}$ and centrifugation. The beads were washed four times with lysis buffer. For Western blot analysis, cell lysates or immunoprecipitates were subjected to SDS-PAGE under reducing conditions and proteins were then transferred to nitrocellulose (Hybond-ECL, Amersham Corp., Arlington Heights, IL) as previously described (4). The membrane was blocked for $2 \mathrm{~h}$ at room temperature with a commercial blocking buffer (GIBCO BRL). The blots were incubated for $1 \mathrm{~h}$ at room temperature with the primary antibodies (anti-ERK1, antiERK2, anti-phosphotyrosine PY20, and anti-FAK from Santa Cruz Biotechnology, Santa Cruz, CA; anti-phosphotyrosine 4G10 from Upstate Biotechnology, Inc., Lake Placid, NY), followed by incubation for 1-2 $\mathrm{h}$ with secondary antibody (horseradish peroxidase conjugated). Immunoreactive bands were visualized by chemiluminescence (ECL; Amersham Life Science, Inc.).

Immunofluorescence staining. HUVEC were detached and resuspended as described above. Before adhesion assay, HUVEC were incubated with $0.1 \%$ dimethylsulfoxide (DMSO; J.T. Baker, Inc., Phillipsburg, NJ), cytochalasin D or nocodazole (Sigma Chemical Co.) for $20 \mathrm{~min}$ at $37^{\circ} \mathrm{C} .10^{6}$ cells were placed onto glass coverslips coated with FN $(10 \mu \mathrm{g} / \mathrm{ml})$ and incubated for $20 \mathrm{~min}$ at $37^{\circ} \mathrm{C}$. The cells were then fixed in $4 \%$ paraformaldehyde in PBS for $20 \mathrm{~min}$ at $37^{\circ} \mathrm{C}$, rinsed with PBS, permeabilized in $0.1 \%$ Triton X-100 in PBS for $10 \mathrm{~min}$ at room temperature, rinsed three times in PBS, and then three times (5 min each) with $50 \mathrm{mM}$ ammonium chloride, $\mathrm{pH}$ 7.3. After rinsing twice with PBS, nonspecific binding was blocked by $1 \%$ BSA in PBS for $30 \mathrm{~min}$, after which the cells were incubated with anti- $\alpha$-tubulin $\mathrm{mAb}$ (Amersham Life Science, Inc.). After three rinses with PBS, biotinylated anti-mouse IgG (Vector Laboratories, Inc., Burlingame, CA) was added for $1 \mathrm{~h}$ at room temperature, rinsed three times in PBS, and incubated with Texas red avidin (Vector Laboratories, Inc.) for $1 \mathrm{~h}$ at room temperature. Filamentous actin (F-actin) was stained with TRITC-labeled phalloidin (Sigma Chemical Co.) for $1 \mathrm{~h}$ at room temperature, followed by three washes in PBS. The coverslips were mounted with mounting media (Vector Laboratories, Inc.), viewed under a phase-fluorescence Nikon microscope, and photographed with TriXPan 400 black and white print film (Eastman Kodak Co., Rochester, NY). There was no cytotoxicity associated with either cytochalasin $\mathrm{D}$ or nocodazole at the concentrations used as shown by trypan blue staining (data not shown).

c-Src immune complex kinase assay. c-Src immune complex kinase assay was performed as described previously (32). Briefly, c-Src immunoprecipitates were washed three times in the buffer described above and twice in kinase reaction buffer (20 mM Pipes, $\mathrm{pH} 7.0,10$ $\mathrm{mmol} /$ liter $\mathrm{MnCl}_{2}$ ). The precipitates were then suspended in the ki-

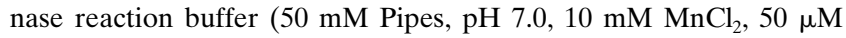
ATP) with $5 \mu \mathrm{g}$ of acid-denatured (with $25 \mathrm{mM}$ sodium acetate, $\mathrm{pH} 3.3,30^{\circ} \mathrm{C}, 5 \mathrm{~min}$ ) rabbit muscle enolase (Sigma Chemical Co.). The kinase reaction (final volume of $50 \mu \mathrm{l}$ ) was started by addition of $10 \mu \mathrm{Ci}\left[\gamma^{-32} \mathrm{P}\right] \mathrm{ATP}$ (specific activity of $6,000 \mathrm{mCi} / \mathrm{mmol}$ ) at $30^{\circ} \mathrm{C}$ and terminated after 10 min by addition of SDS-PAGE sample buffer. Samples were boiled for $5 \mathrm{~min}$, and subjected to SDS-PAGE.

\section{Results}

HUVEC adhesion to FN stimulates ERK1/2. Adhesion of Swiss/ $3 \mathrm{~T} 3$ cells and human skin fibroblasts to FN (a ligand for $\alpha_{3,4,5, \mathrm{v}} \beta_{1}$, 


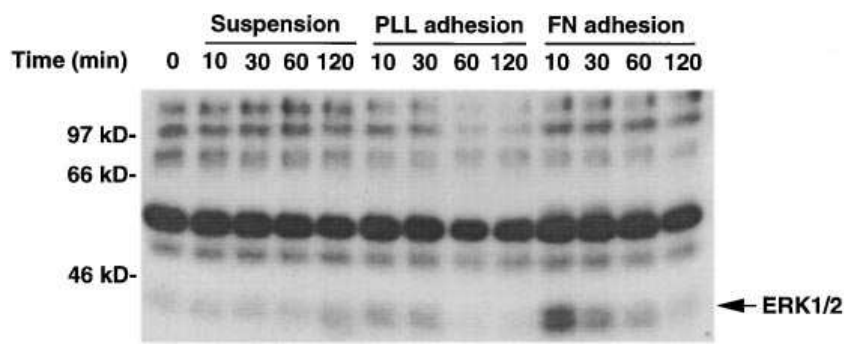

Figure 1. HUVEC adhesion to FN stimulates ERK1/2. HUVEC were grown to confluence, detached with $2 \mathrm{mM}$ EDTA, and then maintained in suspension (Suspension) or placed onto plastic dishes coated with PLL $(10 \mu \mathrm{g} / \mathrm{ml} ;$ PLL Adhesion $)$ or FN $(10 \mu \mathrm{g} / \mathrm{ml} ; F N ~ A d$ hesion) for the indicated times. Cell lysates were prepared and analyzed for ERK1/2 activity using an in-gel-kinase assay.

$\alpha_{\mathrm{v}} \beta_{3}, \alpha_{\mathrm{v}} \beta_{5}$, and $\alpha_{\mathrm{v}} \beta_{6}$ integrins) was recently shown to activate ERK1/2 $(23,24)$. Because we have demonstrated that activating $\beta 1$ integrins directly (with mAb $8 \mathrm{~A} 2 ; 15$ ) stimulates ERK1/2 in HUVEC we determined whether HUVEC adhesion to FN activated ERK1/2. ERK1/2 activity, measured by in-gel-kinase assay, was stimulated by HUVEC adhesion to $\mathrm{FN}$ with peak at $10 \mathrm{~min}$ and return to baseline at $60-120 \mathrm{~min}$ (Fig. 1). No significant activation of ERK1/2 was observed in HUVEC placed onto PLL or maintained in suspension. The differences in ERK1/2 activity under these conditions correlated with cell morphology; HUVEC placed onto FN began to adhere and spread within 10 min, whereas on PLL, HUVEC attached but remained rounded (data not shown).

Shear stress enhances ERK1/2 activation by adhesion. We previously demonstrated that shear stress stimulates a timeand force-dependent activation of ERK1/2 in bovine aortic endothelial cells (4). To examine the effect of shear stress on ERK1/2 activity during adhesion of HUVEC to FN, HUVEC were exposed to flow (shear stress $=12 \mathrm{dyn} / \mathrm{cm}^{2}$ ) for 5, 10, 20, $90 \mathrm{~min}$ after only $10 \mathrm{~min}$ of adhesion. We have previously shown that $12 \mathrm{dyn} / \mathrm{cm}^{2}$ elicits a maximal increase in ERK1/2 activity in HUVEC (15). Peak ERK1/2 activation by shear stress occurred at $5 \mathrm{~min}$ (Fig. 2, $A$ and $B$ ). Concomitant shear stress significantly increased adhesion-mediated ERK1/2 activity by $\sim 50 \%$ (Fig. $2, A-C$ ), with increases in activity in response to adhesion alone (15' Adhesion) of 5.6 \pm 0.9 -fold versus adhesion plus shear stress (Adhesion $10^{\prime}+$ SS $5^{\prime}$ ) of 9.6 \pm 0.9 -fold $(n=3, P<0.05)$. ERK1/2 activation under these conditions was transient with return to baseline within $30 \mathrm{~min}$. Similar results were obtained when ERK1/2 activation was measured by Western blot band shift with anti-ERK1/2 antibodies (data not shown). To investigate whether HUVEC adhesion is necessary for shear stress-induced ERK1/2 activation, suspended cells were stimulated by shear stress for 10 and $30 \mathrm{~min}$ using a rotating shaker. There was no significant ERK1/2 activation in cells exposed to shear stress that were not adherent to a substratum (data not shown). Because the cells plated onto $10 \mu \mathrm{g} / \mathrm{ml}$ PLL-coated dishes were detached by shear stress, cells were placed onto $100 \mu \mathrm{g} / \mathrm{ml}$ PLL-coated dishes and stimulated by shear stress. Adhesion alone to $100 \mu \mathrm{g} / \mathrm{ml}$ PLL stimulated ERK1/2 activation to a small extent, but cells adherent to $100 \mu \mathrm{g} / \mathrm{ml}$ PLL did not show further ERK1/2 activation by shear stress. In addition, we tested the role of RGD binding in shear stress mediated activation of

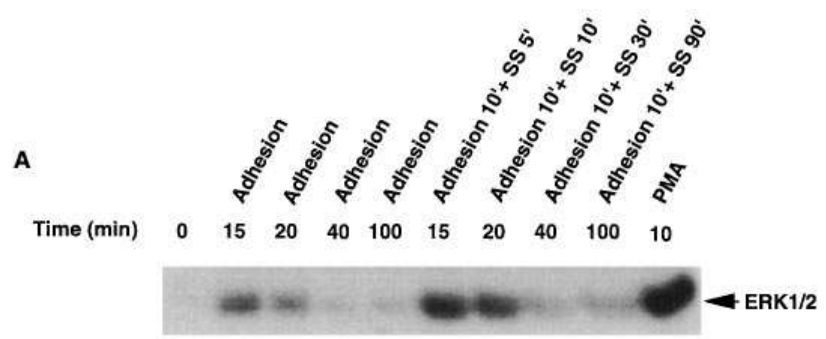

B
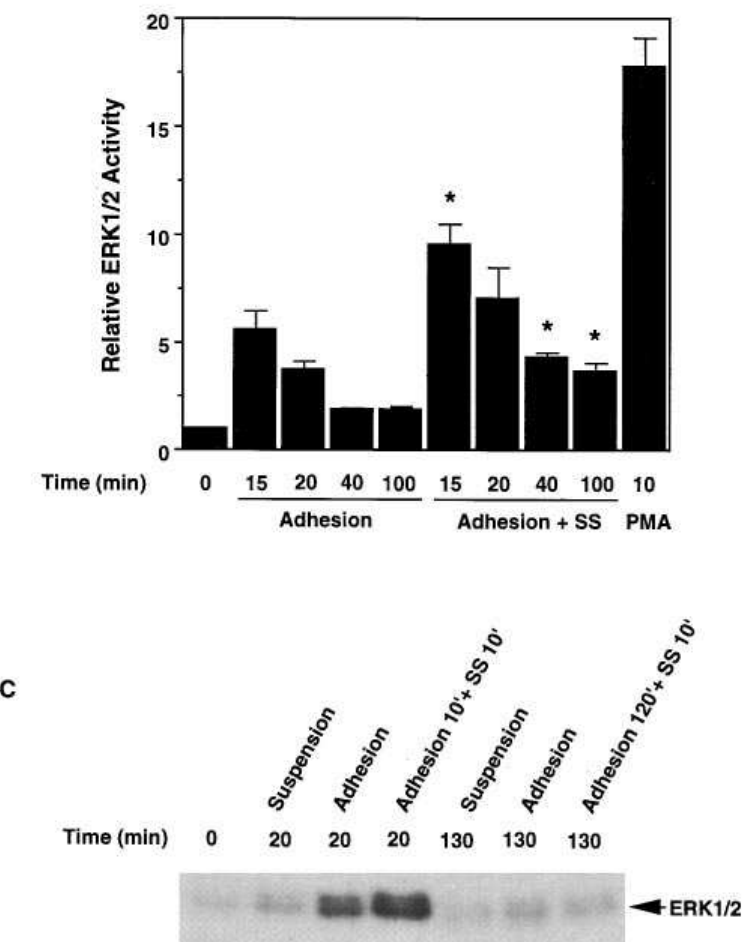

Figure 2. Shear stress enhances ERK1/2 activation by adhesion. In all figures, the Time ( $\mathrm{min}$ ) refers to the total time that cells were allowed to adhere to the dishes. The time of exposure to shear stress $(S S)$ is indicated above each lane. (A) After confluent HUVEC were detached, cells were maintained in suspension (Suspension) or placed onto plastic dishes coated with FN (10 $\mu \mathrm{g} / \mathrm{ml}$; Adhesion) for 15, 20, 40, $100 \mathrm{~min}$. After adherence for $10 \mathrm{~min}$, cells were exposed to shear stress (12 dynes $\left./ \mathrm{cm}^{2} ; S S\right)$ for 5, 10, 20, and $90 \mathrm{~min}$ (Adhesion $10^{\prime}+S S$ $\left.5^{\prime}, 10^{\prime}, 20^{\prime}, 90^{\prime}\right)$. Cell lysates were prepared and analyzed for ERK1/2 activity using an in-gel-kinase assay. (B) Relative ERK1/2 activity was quantified by densitometry. Results are the mean \pm S.E. of three independent experiments. $* P<0.05$ vs. adhesion. $(C)$ After confluent HUVEC were detached, cells were maintained in suspension for 0, 20, $130 \mathrm{~min}$ or placed onto plastic dishes coated with FN $(10 \mu \mathrm{g} / \mathrm{ml}$; Adhesion) for 20 and $130 \mathrm{~min}$. After adherence for 10 and $120 \mathrm{~min}$, cells were exposed to shear stress $\left(12\right.$ dynes $\left./ \mathrm{cm}^{2} ; S S\right)$ for $10 \mathrm{~min}(A d$ hesion $10^{\prime}+S S 10^{\prime}$, Adhesion $\left.120^{\prime}+S S 10^{\prime}\right)$, respectively. Cell lysates were analyzed for ERK1/2 activity using an in-gel-kinase assay.

ERK1/2 by pretreating HUVEC for 30 min with $0.5 \mathrm{mM}$ RGD peptide. Unfortunately, the RGD peptide caused the cells to round up and $>60 \%$ of cells detached when exposed to shear stress, preventing analysis of the role of arg-gly-asp (RGD) binding.

We next determined whether events associated with adhesion modified the ability of HUVEC to respond to shear stress. 

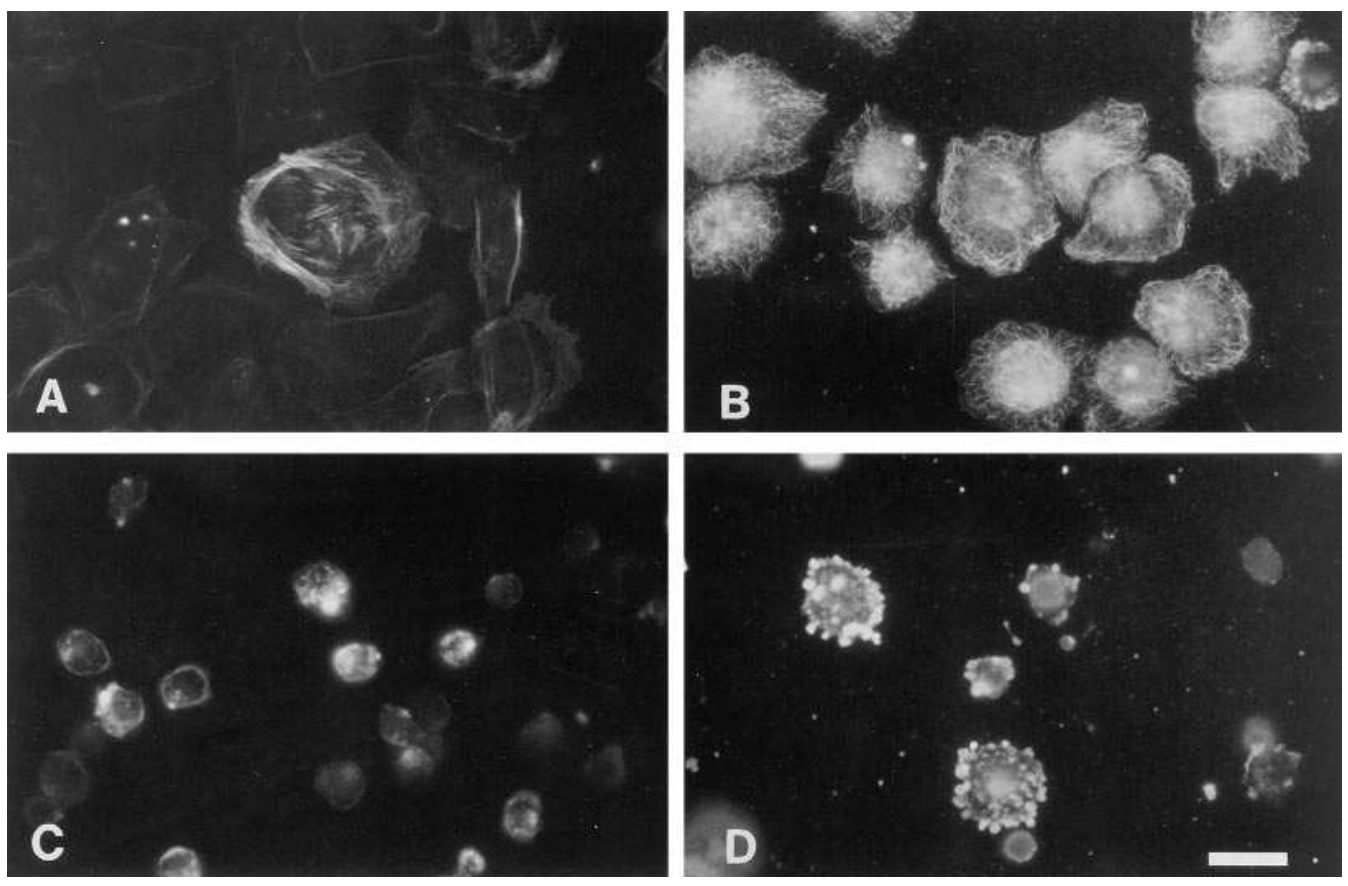

Figure 3. Effect of cytochalasin $\mathrm{D}$ and nocodazole on actin filament and microtubule formation. After confluent HUVEC were detached, suspended cells were pretreated with $0.1 \%$ DMSO ( $A$ and $B$ ), cytochalasin $\mathrm{D}(0.5 \mu \mathrm{M} ; C)$ and nocodazole $(3 \mu \mathrm{M} ; D)$ for 20 $\min$ at $37^{\circ} \mathrm{C}$, and placed onto plastic dishes coated with $\mathrm{FN}(10 \mu \mathrm{g} / \mathrm{ml})$ for $20 \mathrm{~min}$. Cells were fixed, stained for actin filaments $(A$ and $C$ ) and microtubules $(B$ and $D$ ), and analyzed by immunofluorescence microscopy as described in Methods. Bar, $30 \mu \mathrm{m}$.

Shear stress stimulated ERK1/2 activity when HUVEC had adhered for only $10 \mathrm{~min}$, but there was no ERK1/2 stimulation when cells were allowed to adhere for $120 \mathrm{~min}$ before stimulation by shear stress (Fig. 2 B). Phorbol 12-myristate 13-acetate (PMA) stimulated ERK1/2 activation after adhesion for 120 min (data not shown) as well as during the early phase of adhesion, suggesting that there are mechanisms of ERK1/2 desensitization independent of PKC downregulation. At present, this mechanism(s) is unknown.

Effect of cytoskeleton disrupting agents on ERK1/2 activation by adhesion and shear stress. In fibroblasts, ERK1/2 activation by adhesion is inhibited when actin filaments are disrupted $(23,24)$. We therefore investigated the effect of cytoskeleton disrupting agents on ERK1/2 activation by shear stress. Cytochalasin D (0.1 and $0.5 \mu \mathrm{M}$ for $20 \mathrm{~min})$ was used to disrupt actin filaments, and nocodazole ( 1 and $3 \mu \mathrm{M}$ for 20 min) was used to disrupt intermediate filaments and microtubules. HUVEC treated with cytochalasin D and placed on FN for $20 \mathrm{~min}$ attached, but failed to spread as shown by maintenance of a round cell morphology (data not shown). HUVEC treated with vehicle ( $0.1 \%$ DMSO) attached and spread within 20 min. Treatment with nocodazole also inhibited HUVEC spreading as shown by a round cell morphology. The efficacy of these agents, at the indicated concentrations, to disrupt HUVEC cytoskeletal components was confirmed by fluorescence microscopy after staining cells with TRITC-phalloidin and anti- $\alpha$-tubulin antibody (Fig. 3, $A-D$ ). Cytochalasin D at both 0.1 and $0.5 \mu \mathrm{M}$ completely inhibited ERK1/2 activation upon attachment to FN (Fig. $4 A$ ). Cytochalasin D also caused significant inhibition of ERK1/2 activation (44 $\pm 8 \%$ ) by shear stress after adhesion compared with control cells $(P<0.05$, $n=3$, Fig. $4 A$ ). Nocodazole at 1 and $3 \mu \mathrm{M}$ had no inhibitory effect on ERK1/2 activation by either adhesion or shear stress (Fig. $4 B$ ).

ERK1/2 activation by both adhesion and shear stress requires protein kinase $C(P K C)$. PKC may represent a common upstream pathway for ERK1/2 activation by both adhesion and shear stress, because shear stress mediated ERK1/2 activation in bovine aortic endothelial cells (4), and integrin mediated fibroblast spreading (33) are dependent upon PKC. To investigate the role of $\mathrm{PKC}$, we downregulated phorbol ester responsive $\mathrm{PKC}$ isoforms by incubating cells with $1 \mu \mathrm{M}$ phorbol 12, 13 dibutyrate (PDBU) for $24 \mathrm{~h}$. PKC downregulation completely inhibited ERK1/2 activity stimulated by both adhesion and shear stress (Fig. 5). As expected, PMA (200 nM)-

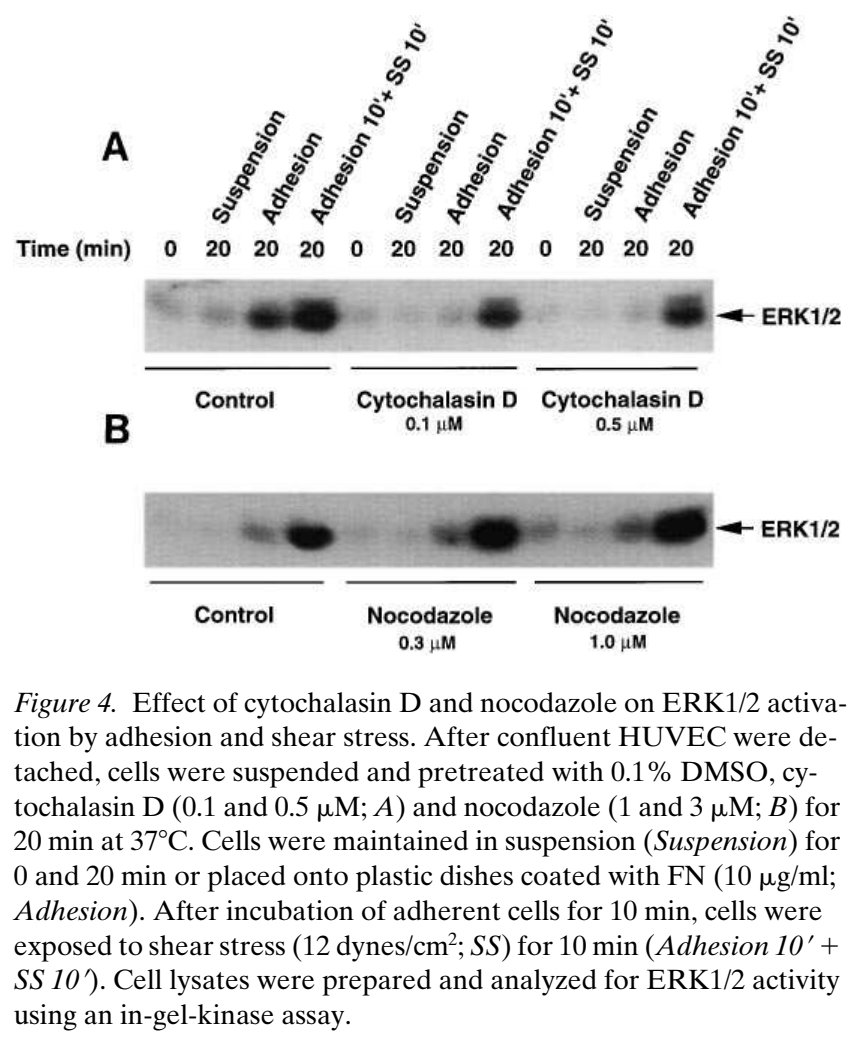




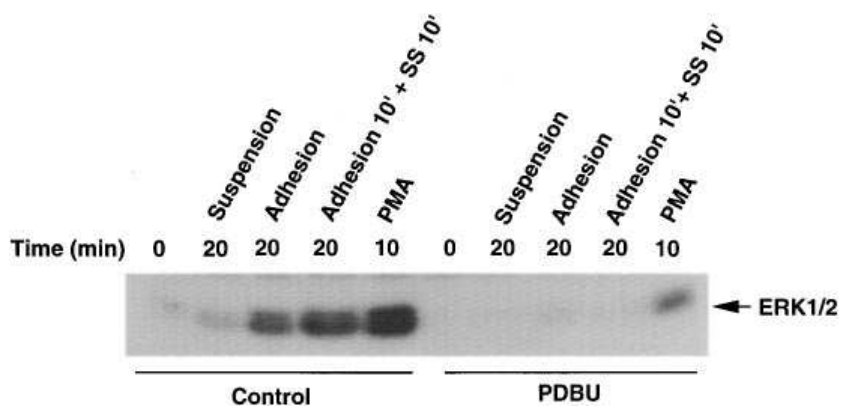

Figure 5. ERK1/2 activation by both adhesion and shear stress requires PKC. HUVEC were pretreated with PDBU $(1 \mu \mathrm{M})$ or $0.1 \%$ DMSO (Control) for $24 \mathrm{~h}$, cells were detached and maintained in suspension (Suspension) for 0 and 20 min or placed onto plastic dishes coated with FN $(10 \mu \mathrm{g} / \mathrm{ml}$; Adhesion $)$ for $20 \mathrm{~min}$. After adherence for $10 \mathrm{~min}$, cells were exposed to shear stress $\left(12\right.$ dynes $\left./ \mathrm{cm}^{2} ; S S\right)$ for 10 min (Adhesion 10' $+S S 10^{\prime}$ ). Cell suspensions were stimulated by PMA $200 \mathrm{nM}$ for $10 \mathrm{~min}$. Cell lysates were analyzed for ERK1/2 activity using an in-gel-kinase assay.

stimulated ERK1/2 activity was also inhibited by pretreatment with PDBU. Adherence and spreading of PKC-downregulated HUVEC to FN-coated plates occurred within $10 \mathrm{~min}$ and the adherent cells showed normal morphology (data not shown).

ERK1/2 activation by adhesion and shear stress is inhibited by herbimycin, but not by genistein or tyrphostin 23 . Because cell adhesion to FN stimulates formation of focal adhesion contacts and increased protein tyrosine phosphorylation (21, 34,35 ), we examined the effect of tyrosine kinase inhibitors on ERK $1 / 2$ activation by adhesion and shear stress. Herbimycin A $(1 \mu \mathrm{M})$ completely inhibited ERK1/2 activation by both adhesion and shear stress (Fig. $6 A$ ). In contrast, neither genistein $(100 \mu \mathrm{M})$ nor tyrphostin $23(100 \mu \mathrm{M})$ inhibited ERK1/2 activation by adhesion and shear stress. The inhibitory effect of herbimycin A was concentration dependent with an $\mathrm{IC}_{50}$ of $\sim 0.1 \mu \mathrm{M}$ (Fig. 6 B).

$c$-Src is activated by adhesion and shear stress. Members of the Src family of protein kinases are readily inhibited by herbimycin A. To determine whether c-Src activity was regulated by shear stress and adhesion, HUVEC were exposed to 12 dynes/ $\mathrm{cm}^{2}$ for varying times, c-Src was immunoprecipitated, and c-Src activity measured by phosphorylation of enolase as described previously (32). Activity of c-Src increased by $2.7 \pm 0.6$-fold within $2 \mathrm{~min}$ in response to shear stress (Figs. 7, $A$ and $C$ ). Cytochalasin $\mathrm{D}(0.5 \mu \mathrm{M})$ had no effect on shear stress-stimulated c-Src activity (Fig. $7 A)$. $\alpha$-thrombin $(10 \mathrm{U} / \mathrm{ml})$ also stimulated c-Src activity to levels comparable to shear stress. Adhesion of HUVEC to FN stimulated c-Src activity (Fig. 7 B). Although adhesion-stimulated c-Src activity was less than shear stressstimulated activity, the results were not statistically different (Fig. $7 \mathrm{C}$ ). To examine the relationship between c-Src and PKC in shear stress-stimulated signaling events, c-Src activity was determined in cells in which PKC was downregulated by treatment with PDBU for $24 \mathrm{~h}$. PKC downregulation had no effect on shear stress-activated c-Src (data not shown). Thus, it is unlikely that PKC is an upstream regulator of c-Src activation by fluid-shear stress.

FAK phosphorylation induced by adhesion and shear stress. FAK may be an important signal mediator in HUVEC because this tyrosine kinase is likely to be activated by both
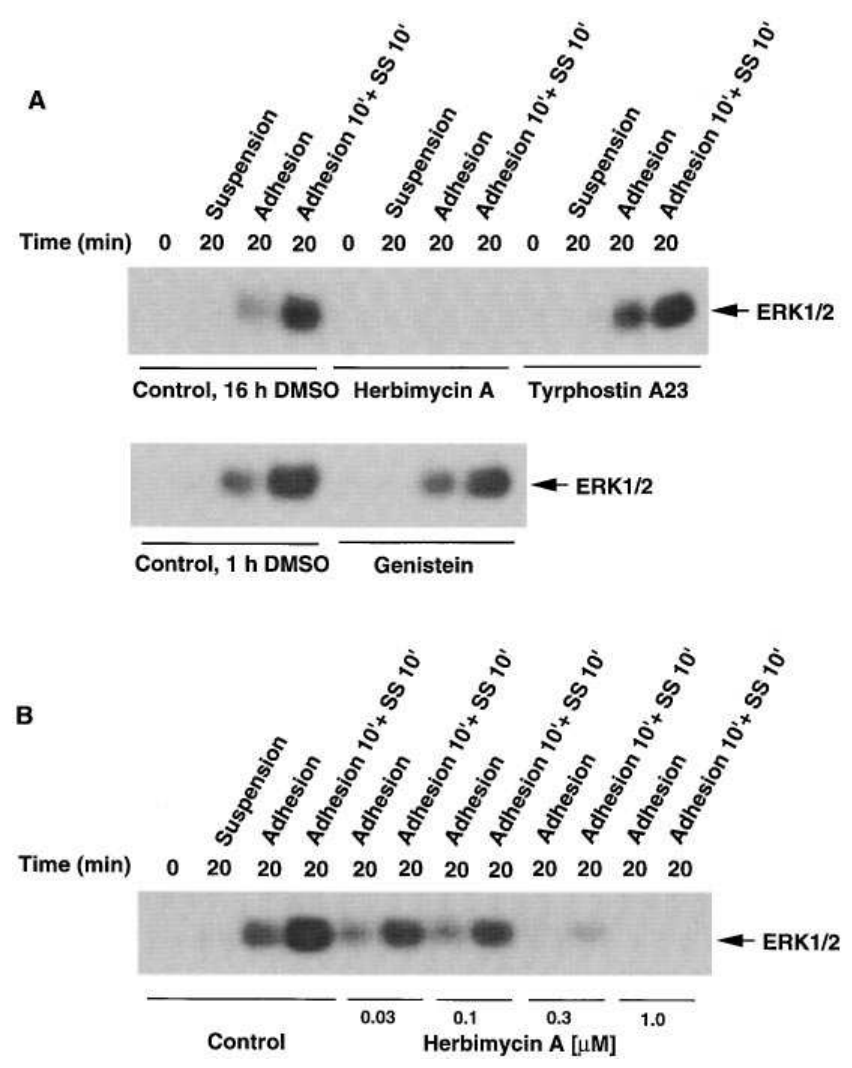

Figure 6. Herbimycin A, but not genistein or tyrphostin 23, inhibits ERK1/2 activation by adhesion and shear stress. $(A)$ Confluent HUVEC were pretreated with $0.1 \%$ DMSO (Control), herbimycin A $(1 \mu \mathrm{M})$, and tyrphostin $23(100 \mu \mathrm{M})$ for $16 \mathrm{~h}($ top $)$ or $0.1 \%$ DMSO (Control) and genistein $(100 \mu \mathrm{M})$ for $1 \mathrm{~h}$ (middle). Cells were detached and maintained in suspension (Suspension) for 0 and $20 \mathrm{~min}$ or placed onto plastic dishes coated with FN $(10 \mu \mathrm{g} / \mathrm{ml}$; Adhesion $)$ for $20 \mathrm{~min}$. After incubation of adherent cells for $10 \mathrm{~min}$, cells were exposed to shear stress (12 dynes/ $\mathrm{cm}^{2} ; S S$ ) for $10 \mathrm{~min}$ (Adhesion $10^{\prime}+$ $\left.S S 10^{\prime}\right)$. Cell lysates were prepared and analyzed for ERK1/2 activity using an in-gel-kinase assay. Treatment by these inhibitors had no effect on cell viability assayed by trypan blue staining (data not shown). (B) Confluent HUVEC were pretreated with $0.1 \%$ DMSO (Control) or herbimycin A $(0.03,0.1,0.3$, and $1.0 \mu \mathrm{M})$ for $16 \mathrm{~h}$. The protocols for adhesion, shear stress, and ERK1/2 activity were as described above.

cell adhesion and shear stress $(15,23,33,34)$. Because FAK may be an upstream component in the pathway leading to ERK1/2 activation (23), we investigated the effects of adhesion and shear stress on FAK tyrosine phosphorylation. FAK phosphorylation, measured by FAK immunoprecipitation and antiphosphotyrosine Western blot analysis, was markedly stimulated within 5 min by HUVEC adhesion to FN (Fig. 8). FAK phosphorylation was sustained for up to $24 \mathrm{~h}$ (data not shown). In contrast, exposure of HUVEC to shear stress after adhesion to FN caused no significant additional increase in FAK phosphorylation at early times (up to 20 min, Fig. 8).

Protein tyrosine phosphorylation stimulated by adhesion and shear stress. Because herbimycin A was an effective inhibitor of ERK1/2 activation we compared proteins whose tyrosine phosphorylation was regulated by adhesion and shear stress in the presence of herbimycin A to identify important 
A

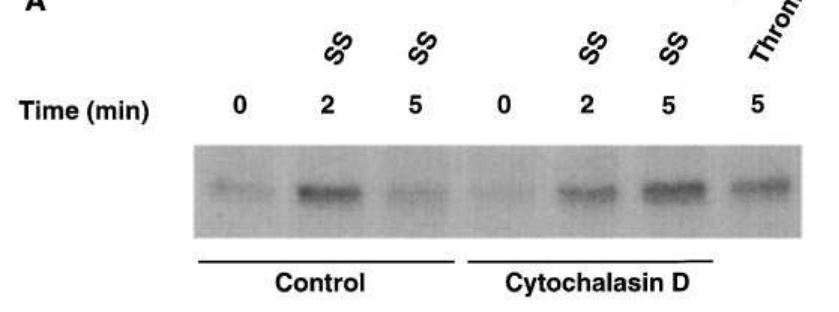

B

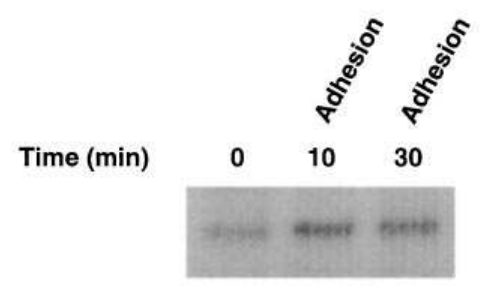

C

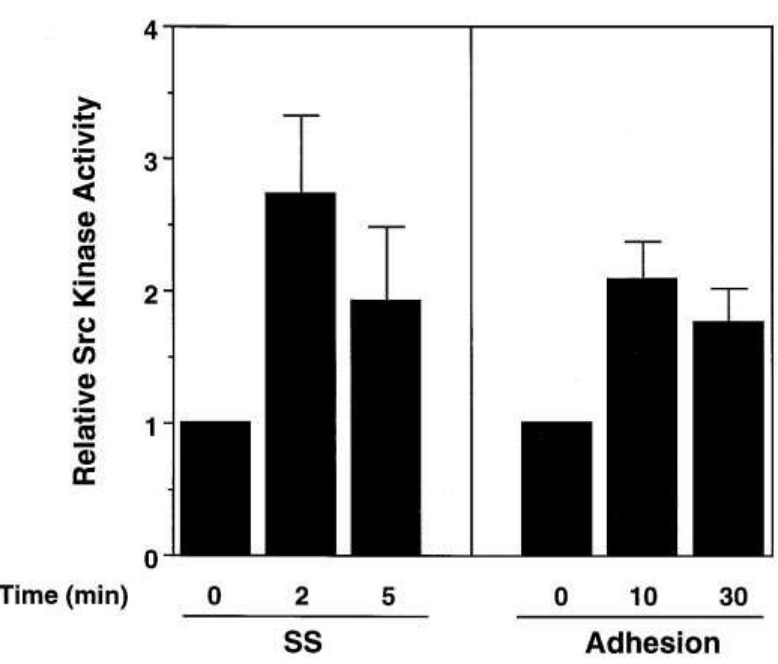

Figure 7. c-Src is activated by adhesion and shear stress. (A) Confluent HUVEC were exposed to shear stress (12 dynes $/ \mathrm{cm}^{2}$; SS) for 2 and 5 min and cell lysates were prepared and analyzed for c-Src activity using immune complex kinase assay. Cells were pretreated with cytochalasin $\mathrm{D}(0.5 \mu \mathrm{M})$ for 20 min prior to shear stress. (B) After confluent HUVEC were detached, cells were placed onto plastic dishes coated with FN $(10 \mu \mathrm{g} / \mathrm{ml}$; Adhesion) for 10 and $30 \mathrm{~min}$ and cell lysates were prepared and analyzed for c-Src activity using immune complex kinase assay. $(C)$ Relative c-Src kinase activity was quantified by densitometry. Results are the mean $\pm \mathrm{SE}$ of three independent experiments. There was no significant difference between shear stress and adhesion.

regulatory kinases. Antiphosphotyrosine Western blot analysis of total cell lysates showed that adhesion to FN stimulated tyrosine phosphorylation of 60-66-, 90-, 110-, and 120-150-kD proteins (Fig. 9). Proteins of 110- and 120-150 kD whose phosphorylation was stimulated by adhesion were not stimulated by shear stress (and in some experiments there was dephosphorylation of these proteins). Shear stress uniquely stimulated tyrosine phosphorylation of a $70-\mathrm{kD}$ protein (Fig. 9). This $70-\mathrm{kD}$ protein is not paxillin, as shown by the failure to detect increased tyrosine phosphorylation by Western blot analysis of paxillin immunoprecipitates (data not shown). Her-

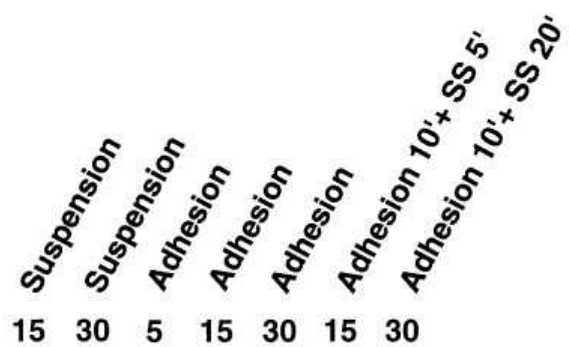

Time (min)

$\begin{array}{llllllll}0 & 15 & 30 & 5 & 15 & 30 & 15 & 30\end{array}$

IP: FAK
IB: PY20

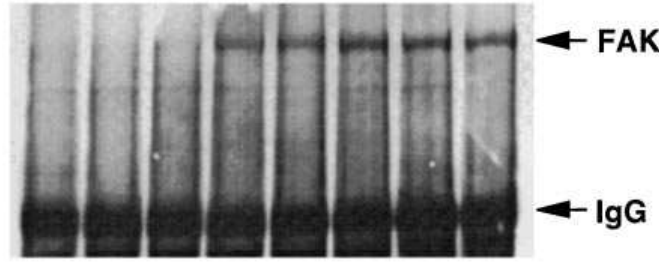

IP: FAK

IB: FAK

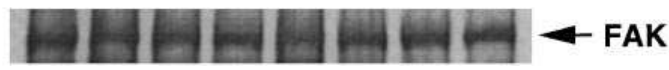

Figure 8. FAK phosphorylation induced by adhesion and shear stress. HUVEC were detached and maintained in suspension (Suspension) or placed onto plastic dishes coated with FN $(10 \mu \mathrm{g} / \mathrm{ml} ; A d$ hesion) for 5, 15, $30 \mathrm{~min}$. For shear stress experiments, after adhesion for $10 \mathrm{~min}$, cells were exposed to shear stress $\left(12 \mathrm{dynes} / \mathrm{cm}^{2} ; S S\right)$ for 5 and 20 min (Adhesion 10' $+S S 5^{\prime}, 20^{\prime}$ ), respectively. Cell lysates were immunoprecipitated with anti-FAK antibody and immunoblotted with antiphosphotyrosine antibody, PY20 (top). The membrane was stripped and reprobed with anti-FAK antibody (bottom).

bimycin $\mathrm{A}(1 \mu \mathrm{M})$ inhibited tyrosine phosphorylation of all proteins shown to be tyrosine phosphorylated by adhesion and shear stress.

\section{Discussion}

The major finding of this study is that ERK1/2 activation by shear stress and by integrin-mediated adhesion to $\mathrm{FN}$ occur via a common pathway in HUVEC that is dependent on PKC and an herbimycin-sensitive tyrosine kinase. Another major finding is that shear stress augments adhesion-mediated ERK1/2 activation by a pathway that is partially independent of actin filament assembly. Together, these findings provide important mechanistic insights into the relationship between integrinECM interactions and shear stress-stimulated mechanotransduction in endothelial cells. The present results are very similar to those reported by Liu et al. (36) regarding the activation of c-Src by mechanical strain in neonatal rat lung fibroblasts. These investigators found that mechanical strain stimulated a PKC- and herbimycin A-sensitive activation of c-Src as well as tyrosine phosphorylation of 110-130-kD cytoskeletal proteins. Yamada et al. $(16,37)$ recently proposed a model for integrinECM signal transduction in which a hierarchy of signal molecules accumulate at sites of integrin activation. Based on this model we discuss below the possibility that activation of tyrosine kinases associated with focal adhesion contacts is a critical early event in flow-mediated signal transduction.

The hypothesis underlying the experiments performed in this study was that integrins play an essential role in mechanotransduction stimulated by shear stress in HUVEC. The rationale for this hypothesis is based on two features charac- 


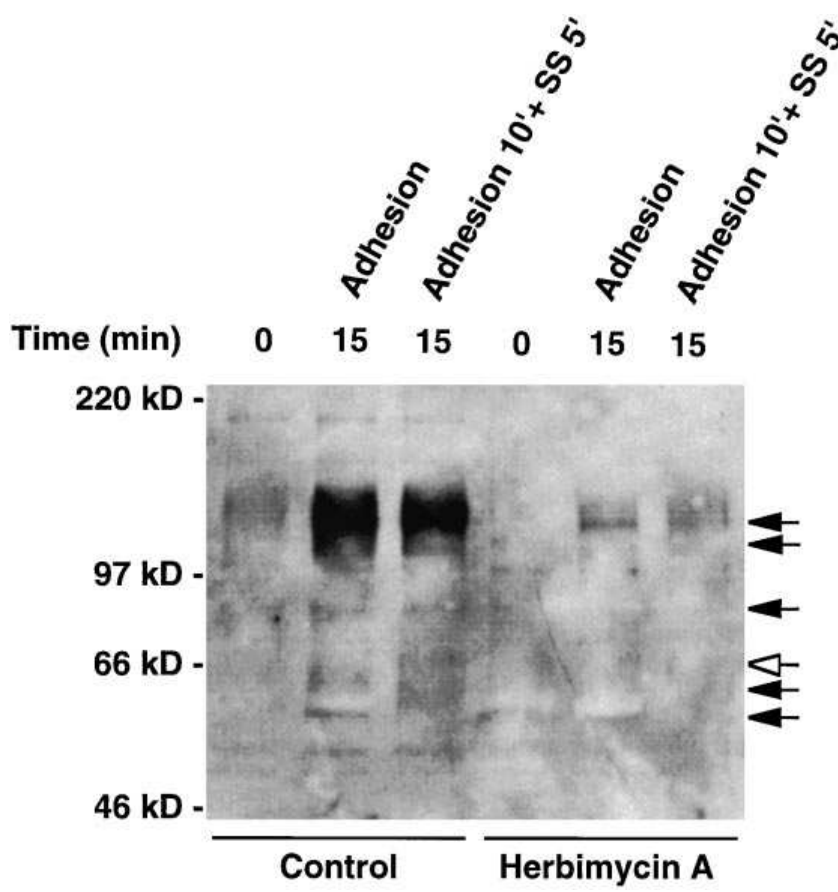

Figure 9. Protein tyrosine phosphorylation stimulated by adhesion and shear stress. Confluent HUVEC were pretreated with $0.1 \%$ DMSO (Control) and herbimycin A $(1 \mu \mathrm{M})$ for $16 \mathrm{~h}$. Cells were detached and placed onto plastic dishes coated with FN $(10 \mu \mathrm{g} / \mathrm{ml} ; A d-$ hesion). For shear stress experiments, after adhesion for $10 \mathrm{~min}$, cells were exposed to shear stress (12 dynes $/ \mathrm{cm}^{2} ; S S$ ) for $5 \mathrm{~min}$ (Adhesion $\left.10^{\prime}+S S 5^{\prime}\right)$. Cell lysates were prepared and Western blot analysis performed with antiphosphotyrosine monoclonal antibody (4G10). Black arrow, adhesion-phosphorylated protein; white arrow, shear stress-phosphorylated protein.

teristic of integrins. First, integrins have the ability to act as mechanotransducers (26). Second, interactions between specific matrix proteins and their integrin receptors stimulate unique, matrix-specific, cellular events. These concepts are supported by data which show that magnetic beads coated with RGD peptides transferred mechanical stress to the cytoskeleton of endothelial cells (25). More recently Ives and colleagues (38) showed that vascular smooth muscle cell growth stimulated by mechanical strain occurred only on ECM-containing collagen, FN, or vitronectin, and growth was abrogated by antibodies against $\beta_{3}$ and $\alpha_{\mathrm{v}} \beta_{5}$ integrins but not by an antibody against $\beta_{1}$ integrins. In the present study we clearly demonstrated that integrin-ECM interactions are required for ERK1/2 activation in HUVEC by mechanical force because ERK1/2 activation occurred when HUVEC adhered to FN, but not to PLL, or when exposed to shear stress in suspension. Finally, it is important to note that in the present study, HUVEC were stimulated by shear stress after adhesion to FN for only 10-120 min. This novel assay system should be useful to analyze the role of specific ECM components in shear stress-mediated events, because cells cannot synthesize their own matrices during the time course of the experiment $(<2 \mathrm{~h})$.

The present study suggests that ERK1/2 activation by adhesion to $\mathrm{FN}$ occurs via $\beta_{1}$ integrins, although we have not ruled out the possibility that other classes of integrins (e.g., $\beta_{3}$ and $\beta_{5}$ ) contribute to the response. It has been reported that FN interacts with several integrins including $\alpha_{3,4,5, \mathrm{v}} \beta_{1}, \alpha_{\mathrm{v}} \beta_{3}$, $\alpha_{v} \beta_{5}$, and $\alpha_{v} \beta_{6}$ (39). In this regard, we recently found that $8 \mathrm{~A} 2$, a soluble monoclonal antibody that activates $\beta_{1}$ integrins, also stimulates ERK1/2 in HUVEC (15). We also found that HUVEC adhesion to FN stimulated ERK1/2 activation with peak at $10 \mathrm{~min}$. Previous reports described maximal activation of ERK1/2 by adhesion at 20-40 min with Swiss 3T3 cells (23), which are likely to express different integrins than HUVEC. In this regard, we observed that adhesion and spreading of Swiss $3 \mathrm{~T} 3$ cells to FN took significantly longer than HUVEC adhesion and spreading.

Actin filament assembly plays an important role in integrin-mediated signaling events (20) and has been shown to be required for mechanostransduction. For instance, Ingber and colleagues (25) demonstrated that cytoskeleton disrupting agents such as cytochalasin D inhibited mechanical stress-induced cytoskeleton stiffening. Furthermore, Watson (40) reported that deformation-mediated stimulation of stretch-activated ion channels was inhibited by disruption of actin filaments. Liu et al. (36) showed that mechanical strain stimulated c-Src translocation and association with actin cytoskeleton, especially the actin binding protein, AFAP 110. These investigators also showed that cytochalasin B inhibited strain induced c-Src translocation suggesting an important role for actin filament assembly. Several investigators have reported that disrupting actin filaments with cytochalasin D blocked adhesion-mediated ERK1/2 activation $(23,24)$. We also found that cytochalasin D completely blocked ERK1/2 activation upon HUVEC adhesion to FN (Figs. 3 and 4). However, cytochalasin D inhibited shear stress-induced ERK1/2 activation by only $44 \%$ at the same concentration which completely blocked ERK1/2 activation by adhesion. This finding indicates that shear stress activated ERK1/2 via a pathway that is partially independent of actin assembly. The nature of this actin assembly independent pathway remains undefined although the large number of proteins suggested to be involved in mechanotransduction (27) provide many candidate molecules.

Activation of tyrosine kinases and phosphorylation of 110 $130-\mathrm{kD}$ proteins is a characteristic feature of signal transduction activated by integrin clustering and cell adhesion (20). However, the tyrosine kinase(s) responsible for mechanotransduction remain undefined. The present study, as well as Liu et al. (36), found that c-Src was activated by mechanical forces. The finding that ERK1/2 activity by adhesion and shear stress was inhibited by herbimycin A, a Src family kinase inhibitor, suggests that c-Src activity is functionally important. Of interest, Liu et al. (36) also found that herbimycin A blocked tyrosine phosphorylation of PLC- $\gamma$, a c-Src substrate, induced by mechanical strain. FAK is another candidate tyrosine kinase that may mediate mechanotransduction. It has been reported that tyrosine phosphorylation of FAK and the FAK substrate, paxillin, accompanies cell adhesion to FN (20). However, it does not appear that FAK is the tyrosine kinase upstream of ERK1/2 as FAK activation by shear stress was significantly slower (15) and of smaller magnitude when compared to adhesion (Fig. 8). Liu et al. (36) also observed no increase in FAK phosphorylation in response to mechanical strain. Taken together these results suggest that c-Src, but not FAK, is likely to be involved in the rapid cellular response to mechanical forces.

The findings that shear stress activates ERK1/2 to a greater 
extent than adhesion to $\mathrm{FN}$ alone and that shear stress does not require actin filament assembly, indicates that shear stress stimulates additional signal events that converge upon ERK1/2. Two possible pathways for convergent signal transduction involve PKC and tyrosine kinase mediated events. With respect to PKC, both our laboratory (4) and Chein's laboratory (41) previously demonstrated that shear stress stimulation of ERK1/2 activity is PKC-dependent in bovine aortic endothelial cells. Integrin activation also stimulates PKC, although the specific isozymes activated by shear stress and integrins remain to be defined. In terms of tyrosine kinases, we observed that the potency of tyrosine kinase inhibitors (herbimycin $>>$ genistein $>$ tyrphostin 23 ) was identical for adhesion and shear stress, suggesting that the same tyrosine kinase might be involved in adhesion-induced and shear stress-induced ERK1/2 activation. A model for cell proliferation that includes convergent effects of growth factors and cell adhesion has been proposed by Schwartz et al. (17). We propose a modification of this model based on the concept that shear stress activates both c-Src-dependent and integrin-dependent events which converge at ERK1/2. In this model, Src activation causes Shc phosphorylation, binding of GRB2, and activation of Sos and Ras. Activation of Ras causes Raf translocation and activation leading to ERK1/2 activation (42). Conversely, integrin activation causes recruitment of multiple proteins to focal adhesion contacts including GRB2 (43), and integrin activation has been shown to activate Ras in NIH 3 T3 fibroblasts (44) which leads to ERK1/2 activation as described above. The importance of this pathway in shear stress signal transduction is suggested by the preliminary report that flow activates Ras in endothelial cells (45). Future studies will be required to identify the molecules recruited to focal adhesion contacts in response to shear stress.

In summary, the present study in concert with work of others (36) suggest that the rapid events stimulated by mechanical force (e.g., shear stress, mechanical strain, and cell adhesion) share a common herbimycin A-sensitive pathway. We propose that $\mathrm{c}-\mathrm{Src}$ is an important component of this pathway. However, shear stress and strain differ from adhesion by their relative lack of dependence on FAK phosphorylation. Shear stress and strain differ in that shear stress-mediated activation of ERK1/2 is less dependent than strain on the integrity of actin filament assembly. These results suggest that there are several mechanotransduction sensors and pathways, a concept supported by genetic studies in Caenorhabditus elegans where at least 12 genes involved in mechanotransduction have been identified (46). Understanding the mechanisms by which c-Src is activated by mechanical forces should provide important insight into the nature of these mechanosensors in mammalian cells.

\section{Acknowledgments}

We would like to thank M. Saito for the discussion about immunofluorescence study and members of the Berk laboratory (especially Drs. T. Ishida, M. Kusuhara, M. Ishida, J. Abe and T.E. Peterson) for their help.

This study was supported by a Banyu Fellowship Award in Lipid Metabolism and Atherosclerosis to $\mathrm{M}$. Takahashi and grants from the National Institutes of Health (PO1-HL18645) to B.C. Berk. Dr. Berk is an Established Investigator of the American Heart Association.

\section{References}

1. Davies, P.F. 1995. Flow-mediated endothelial mechanotransduction. Physiol. Rev. 75:519-560.

2. Geiger, R.V., B.C. Berk, R.W. Alexander, and R.M. Nerem. 1992. Flowinduced calcium transients in single endothelial cells: spatial and temporal analysis. Am. J. Physiol. 262:C1411-C1417.

3. Shen, J., F.W. Luscinskas, A. Connolly, C.F.J. Dewey, and M.A.J. Gimbrone. 1992. Fluid shear stress modulates cytosolic free calcium in vascular endothelial cells. Am. J. Physiol. 262:C384-C390.

4. Tseng, H., T. Peterson, and B.C. Berk. 1995. Fluid shear stress stimulates mitogen-activated protein kinases in bovine aortic endothelial cells. Circ. Res. 77:869-878.

5. Yi-Shuan, L., Y.-J. John, and S. Shyy. 1995. The cytoplasmic kinase pathways are involved in the shear stress-induced gene expression. Circulation. 92:I-1.

6. Ranjan, V., and S.L. Diamond. 1993. Fluid shear stress induces synthesis and nuclear localization of c-fos in cultured human endothelial cells. Biochem. Biophys. Res. Commun. 196:79-84.

7. Hsieh, H.-J., N.-Q. Li, and J.A. Frangos. 1992. Shear-induced plateletderived growth factor gene expression in human endothelial cells is mediated by protein kinase C. J. Cell Physiol. 150:552-558.

8. Shyy, Y.J., H.J. Hsieh, S. Usami, and S. Chien. 1994. Fluid shear stress induces a biphasic response of human monocyte chemotactic protein 1 gene expression in vascular endothelium. Proc. Natl. Acad. Sci. USA. 91:4678-4682.

9. Malek, A., and S. Izumo. 1992. Physiological fluid shear stress causes downregulation of endothelin-1 mRNA in bovine aortic endothelium. Am. J. Physiol. 263:C389-C396.

10. Ray, L.B., and T.W. Sturgill. 1987. Rapid stimulation by insulin of a serine/threonine kinase in 3T3-L1 adipocytes that phosphorylates microtubuleassociated protein 2 in vitro. Proc. Natl. Acad. Sci. USA. 84:1502-1506.

11. Chen, R.-H., C. Sarnecki, and J. Blenis. 1992. Nuclear localization and regulation of erk-and rsk-encoded protein kinases. Mol. Cell Biol. 12:915-927.

12. Sturgill, T.W., B.L. Ray, E. Erikson, and J.L. Maller. 1988. Insulin-stimulated MAP-2 kinase phosphorylates protein S6 kinase II. Nature (Lond.). 334: 715-718.

13. Gille, H., A.D. Sharrocks, and P.E. Shaw. 1992. Phosphorylation of transcription factor p62TCF by MAP kinase stimulates ternary complex formation at c-fos promoter. Nature (Lond.). 358:414-417.

14. Lange-Carter, C.A., C.M. Pleiman, A.M. Gardner, K.J. Blumer, and G.L. Johnson. 1993. A divergence in the MAP kinase regulatory network defined by MEK kinase and raf. Science (Wash. DC). 260:315-319.

15. Ishida, T., T.E. Peterson, N. Kovach, and B.C. Berk. 1996. MAP kinase activation by flow in endothelial cells: role of $\beta 1$ integrins and tyrosine kinases. Circ. Res. 79:310-316.

16. Yamada, K.M., and S. Miyamoto. 1995. Integrin transmembrane signaling and cytoskeletal control. Curr. Opin. Cell Biol. 7:681-689.

17. Ingber, D.E., D. Prusty, J.V. Frangioni, E.J. Cragoe Jr., C. Lechene, and M.A. Schwartz. 1990. Control of intracellular $\mathrm{pH}$ and growth by fibronectin in capillary endothelial cells. J. Cell Biol. 110:1803-1811.

18. Schwartz, M.A., D.E. Ingber, M. Lawrence, T.A. Springer, and C. Lechene. 1991. Multiple integrins share the ability to induce elevation of intracellular pH. Exp. Cell Res. 195:533-535.

19. Schwartz, M.A. 1993. Spreading of human endothelial cells on fibronectin or vitronectin triggers elevation of intracellular free calcium. J. Cell Biol. 120:1003-1010.

20. Burridge, K., C.E. Turner, and L.H. Romer. 1992. Tyrosine phosphorylation of paxillin and $\mathrm{pp} 125^{\mathrm{FAK}}$ accompanies cell adhesion to extracellular matrix: A role in cytoskeletal assembly. J. Cell Biol. 119:893-903.

21. Hanks, S.K., M.B. Calalb, M.C. Harper, and S.K. Patel. 1992. Focal adhesion protein-tyrosine kinase phosphorylated in response to cell attachment to fibronectin. Proc. Natl. Acad. Sci. USA. 89:8487-8491.

22. Nollert, M.U., S.G. Eskin, and L.V. McIntire. 1990. Shear stress increases inositol trisphosphate levels in human endothelial cells. Biochem. Biophys. Res. Commun. 170:281-287.

23. Chen, O., M.S. Kinch, T.H. Lin, K. Burridge, and R.L. Juliano. 1994. Integrin-mediated cell adhesion activates mitogen-activated protein kinases. $J$. Biol. Chem. 269:26602-26605.

24. Morino, N., T. Mimura, K. Hamasaki, K. Tobe, K. Ueki, K. Kikuchi, K. Takehara, T. Kadowaki, Y. Yazaki, and Y. Nojima. 1995. Matrix/integrin interaction activates the mitogen-activated protein kinase, $\mathrm{p} 44^{\text {erk-1 }}$ and $\mathrm{p} 42^{\text {erk-2}} . J$. Biol. Chem. 270:269-273.

25. Wang, N., J.P. Butler, and D.E. Ingber. 1993. Mechanotransduction across the cell surface and through the cytoskeleton. Science (Wash. DC). 260: 1124-1127.

26. Ingber, D. 1991. Integrins as mechanochemical transducers. Curr. Opin. Cell Biol. 3:841-848.

27. Davies, P.F., and S.C. Tripathi. 1993. Mechanical stress mechanisms and the cell. An endothelial paradigm. Circ. Res. 72:239-245.

28. Davies, P.F., A. Robotewskyj, and M.L. Griem. 1993. Endothelial cell adhesion in real time-measurements in vitro by tandem scanning confocal image analysis. J. Clin. Invest. 91:2640-2652. 
29. Davies, P.F., A. Robotewskyj, and M.L. Griem. 1994. Quantitative studies of endothelial cell adhesion. Directional remodeling of focal adhesion sites in response to flow forces. J. Clin. Invest. 93:2031-2038.

30. Gimbrone, M.A. Jr. 1976. Culture of vascular endothelium. Prog. Hemostasis Thromb. 3:1-28.

31. Duff, J.D., B.P. Monia, and B.C. Berk. 1995. Mitogen-activated protein (MAP) kinase is regulated by the MAP kinase phosphatase (MKP-1) in vascular smooth muscle cells. J. Biol. Chem. 270:7161-7166.

32. Ishida, M., M.B. Marrero, B. Schieffer, T. Ishida, K.E. Bernstein, and B.C. Berk. 1995. Angiotensin II activates pp60 $0^{\text {c-src }}$ in vascular smooth muscle cells. Circ. Res. 77:1053-1059.

33. Vuori, K., and E. Ruoslahti. 1993. Activation of protein kinase C precedes alpha5beta1 integrin-mediated cell spreading on fibronectin. J. Biol. Chem. 268:21459-21462.

34. Guan, J.L., J.E. Trevithick, and R.O. Hynes. 1991. Fibronectin/integrin interaction induces tyrosine phosphorylation of a $120-\mathrm{kDa}$ protein. Cell Regul. 2:951-964.

35. Plopper, G., and D.E. Ingber. 1993. Rapid induction and isolation of focal adhesion complexes. Biochem. Biophys. Res. Commun. 193:571-578.

36. Liu, M., Y. Qin, A.K. Tanswell, and M. Post. 1996. Mechanical strain induces pp60src activation and translocation to cytoskeleton in fetal rat lung cells. J. Biol. Chem. 271:7066-7071.

37. Miyamoto, S., H. Teramoto, O.A. Coso, J.S. Gutkind, P.D. Burbelo, S.K. Akiyama, and K.M. Yamada. 1995. Integrin function: Molecular hierarchies of cytoskeletal and signaling molecules. J. Cell Biol. 131:791-805.
38. Wilson, E., K. Sudhir, and H.E. Ives. 1995. Mechanical strain of rat vascular smooth muscle cells is sensed by specific extracellular matrix/integrin interactions. J. Clin. Invest. 96:2364-2372.

39. Hynes, R.O. 1992. Integrins: versatility, modulation, and signaling in cell adhesion. Cell. 69:11-25.

40. Watson, P.A. 1991. Function follows form: generation of intracellular signals by cell deformation. FASEB J. 5:2013-2019.

41. Shyy, J.Y., M.C. Lin, J. Han, Y. Lu, M. Petrime, and S. Chien. 1995. The cis-acting phorbol ester "12-O-tetradecanoylphorbol 13-acetate"-responsive element is involved in shear stress-induced monocyte chemotactic protein 1 gene expression. Proc. Natl. Acad. Sci. USA. 92:8069-8073.

42. Pelech, S.L., and J.S. Sanghera. 1992. MAP kinases: charting the regulatory pathways. Science (Wash. DC). 257:1355-1356.

43. Schlaepfer, D.D., S.K. Hanks, T. Hunter, and P. van der Geer. 1994. Integrin-mediated signal transduction linked to Ras pathway by GRB2 binding to focal adhesion kinase. Nature (Lond.). 372:786-791.

44. Clark, E.A., and R.O. Hynes. 1996. Ras activation is necessary for integrin-mediated activation of extracellular signal-regulated kinase 2 and cytosolic phospholipase $\mathrm{A}_{2}$ but not for cytoskeletal organization. J. Biol. Chem. 271: 14814-14818.

45. Li, Y.S., Y.J. Shyy, and S. Chien. 1995. The cytoplasmic kinase pathways are involved in the shear stress-induced gene expression. Circulation. 92:I-1.

46. Corey, D.P., and J. Garcia-Anoveros. 1996. Mechanosensation and the DEG/ENaC ion channels. Nature (Lond.). 273:323-324. 